\title{
Cell Death and Recovery in Traumatic Brain Injury
}

\author{
Yosuke Akamatsu ${ }^{1,2} \cdot$ Khalid A. Hanafy ${ }^{3,4}$ \\ Published online: 13 February 2020 \\ (C) The American Society for Experimental NeuroTherapeutics, Inc. 2020
}

\begin{abstract}
Traumatic brain injury (TBI) is the leading cause of morbidity and mortality worldwide. Although TBI leads to mechanical damage during initial impact, secondary damage also occurs as results from delayed neurochemical process and intracellular signaling pathways. Accumulated animal and human studies demonstrated that apoptotic mechanism contributes to overall pathology of TBI. Apoptotic cell death has been identified within contusional brain lesion at acute phase of TBI and in region remote from the site directly injured in days to weeks after trauma. TBI is also dynamic conditions that cause neuronal decline overtime and is likely due to neurodegenerative mechanisms years after trauma. Current studies have even suggested association of neuronal damage through apoptotic pathway with mild TBI, which contributes chronic persistent neurological symptoms and cognitive deficits. Thus, a better understanding of the acute and chronic consequences of apoptosis following TBI is required. The purpose of this review is to describe (1) neuronal apoptotic pathway following TBI, (2) contribution of apoptosis to acute and chronic phase of TBI, and (3) current treatment targeting on apoptotic pathway.
\end{abstract}

Keywords Cell death $\cdot$ Recovery $\cdot$ Traumatic brain injury

\section{Introduction}

Traumatic brain injury (TBI) is a significant cause of morbidity and mortality [1]. TBI is caused by primary and secondary brain damage resulting in loss of neurons, astrocytic gliosis, and microglial activation which all culminate in complex neurological disorders [2]. Although primary brain damage is caused by mechanical damage during initial impact and is considered irreversible, secondary damage results from delayed neurochemical process and intracellular signaling pathways, which is reversible. Increases in neuronal damage during the chronic phase of TBI have been implicated in secondary brain damage and poor outcome [3-6].

Khalid A. Hanafy

khanafy@bidmc.harvard.edu

1 Division of Neurosurgery, Beth Israel Deaconess Medical Center, Harvard Medical School, Boston, MA, USA

2 Department of Neurosurgery, Iwate Medical University, Morioka, Japan

3 Department of Neurology, Harvard Medical School, Boston, MA, USA

4 Division of Neurointensive Care, Beth Israel Deaconess Medical Center, Harvard Medical School, 3 Blackfan Circle Rm 639, Boston, MA 02115, USA
Apoptosis is defined as programmed cell death mediated by mitochondria in particular, and result in internucleosomal DNA fragmentation, detectable by in situ using the terminal deoxynucleotidyl transferase-mediated dUTP nick endlabeling (TUNEL) [7]. Since apoptotic neuronal death is a mechanism to remove unnecessary neurons with minimal activation of immune system, neuronal apoptosis following a traumatic insult could represent a physiological and protective response to damage. However, transgenic mice overexpressing an anti-apoptotic protein showed a significant reduction in cortical and hippocampal damage following TBI $[8,9]$. Therefore, excessive activation of apoptosis-related pathway could be harmful, especially in pathological conditions. Accumulated preclinical studies have revealed that neuronal cell death was observed in the pericontusional region and the hippocampus [10-12]. Interestingly, using the moderate lateral fluid-percussion brain injury model, apoptotic cells in the injured cortex was noted at as early as $24 \mathrm{~h}$, whereas in the hippocampus and the thalamus, apoptotic response was delayed, peaking at $48 \mathrm{~h}$ and 2 weeks after injury, respectively [13]. In contrast, using controlled cortical impact (CCI) model, neuronal apoptotic cells were the most apparent in the contusional region and hippocampus at between 24 and $48 \mathrm{~h}$ after injury [13-15]. Furthermore, the functional outcome was correlated with severity of the 
Table 1 Spatiotemporal distribution of neuronal cell death in preclinical and clinical study

\begin{tabular}{|c|c|c|c|c|c|c|c|}
\hline Author & Species & $\begin{array}{l}\text { TBI } \\
\text { model }\end{array}$ & Severity & $\begin{array}{l}\text { Location of } \\
\text { neuronal loss }\end{array}$ & $\begin{array}{l}\text { Type of } \\
\text { cell death }\end{array}$ & Time point & Neurological outcome \\
\hline \multirow[t]{2}{*}{ Conti [10] } & Rat & FPI & Moderate & $\begin{array}{l}\text { Cortex, } \\
\text { Hippocampus }\end{array}$ & Apoptosis & $\begin{array}{l}24 \mathrm{~h} \text { and } 1 \text { weeks } \\
48 \mathrm{~h}\end{array}$ & NA \\
\hline & & & & Thalamus & & 2 weeks & \\
\hline Clark [11] & Rat & $\mathrm{CCI}$ & Moderate & Cortex and Hippocampus & Apoptosis & $24 \mathrm{~h}$ & NA \\
\hline Kaya [12] & Rat & $\mathrm{CCI}$ & Moderate & $\begin{array}{l}\text { Cortex and } \\
\text { hippocampus }\end{array}$ & Apoptosis & $48 \mathrm{~h}$ & NA \\
\hline Fox [13] & Mouse & $\mathrm{CCI}$ & Mild and moderate & $\begin{array}{l}\text { Cortex and } \\
\text { hippocampus }\end{array}$ & Apoptosis & $24 \mathrm{~h}$ & $\begin{array}{l}\text { Deficit in sensory/motor } \\
\text { function and spatial learning } \\
\text { in moderate TBI }\end{array}$ \\
\hline Dixon [14] & Rat & $\mathrm{CCI}$ & Mild, moderate, severe & $\begin{array}{l}\text { Cortex and } \\
\text { hippocampus }\end{array}$ & Not specified & 5 days & $\begin{array}{l}\text { Deficit in vestibulomotor } \\
\text { function in response } \\
\text { to injury severity }\end{array}$ \\
\hline Hamm [15] & Rat & CCI & Severe & $\begin{array}{l}\text { Cortex and } \\
\text { hippocampus }\end{array}$ & Not specified & 35 days & Deficit in spatial memory \\
\hline
\end{tabular}

$C C I$ controlled cortical impact, FPI fluid percussion injury, NA not available

injury [13-15]. Therefore, the type, extent, and spatiotemporal distribution of neuronal apoptosis could be related to injury type and severity (Table 1). This pericontusional and hippocampal apoptosis was also confirmed in post-traumatic human brain tissue [16-19]. Here we review accumulated evidence for apoptosis following TBI.

\section{Intrinsic Pathway of Neuronal Apoptosis}

Mitochondria trigger a variety of apoptotic signaling pathways, via interactions among the bcl-2 family proteins, such as cytochrome c, apoptosis-inducing factor (AIF), endonuclease $\mathrm{G}$ (Endo G), and second mitochondria-derived activator of caspase (Smac), to release pro-apoptotic proteins from the intermembrane of mitochondria, which result in apoptosis [20]. This pathway is called the intrinsic pathway.

\section{$\mathrm{Ca}^{2+}$ Channel-Mediated Apoptosis}

TBI induces depletion of energy leading to a loss of membrane potential and depolarization of neurons. Subsequently, voltage-gated $\mathrm{Ca}^{2+}$ channels are activated and excitatory amino acids are released into the extracellular space [21]. Intracellular $\mathrm{Ca}^{2+}$ concentration increases and initiates cytoplasmic and nuclear events, involving the intrinsic apoptotic pathway [22]. An immediate response to increased intracellular $\mathrm{Ca}^{2+}$ is the activation of neutral proteases, calpain, which have been implicated in the cleaving of Bcl-2 interaction domain (bid) and its truncated active form (tBID) in ischemic stroke $[23,24]$. However, in vitro studies suggest that activation of calpain could be associated with necrosis rather than apoptosis in the setting of TBI, although calpain activation may induce apoptosis to some extent $[25,26]$. Elevated intracellular $\mathrm{Ca}^{2+}$ is also associated with activation of the caspase gene family, leading to the induction of apoptosis [27]. $\mathrm{Ca}^{2+}$-dependent endonucleases are also activated following TBI, causing DNA damage in the form of the orderly chromatin cleavage patterns which are typical of apoptosis [28]. However, since therapeutic strategies aimed at inhibiting absolute intracellular $\mathrm{Ca}^{2+}$ elevations, such as voltage-gated calcium channels, were efficient in a clinical setting [28], further research should target intracellular $\mathrm{Ca}^{2+}$ signaling pathways and $\mathrm{Ca}^{2+}$ homeostasis following TBI.

\section{Bcl-2 Family Proteins and Mitochondria}

Mitochondria are critical to the apoptotic pathway by releasing pro-apoptotic factors from its intermembrane space into the cytoplasm. Bcl-2 family protein, stored in the mitochondrial intermembrane, is a principal regulator of mitochondrial membrane integrity and function. The $\mathrm{Bcl}-2$ protein family is classified into three groups by structural homology: the antiapoptotic proteins such as Bcl-2, Bcl-XL, and Bcl-w; the proapoptotic proteins such as Bax; and the $\mathrm{BH} 3$-only proteins including Bad, Bid, Bim, Noxa, and p53-upregulated modulator of apoptosis (PUMA) [20]. Two main theories have been described to explain Bcl-2 protein family interaction: the "direct model" and the "hierarchy model." In the former model, anti-apoptotic proteins can inhibit pro-apoptotic proteins. This interaction is disrupted by $\mathrm{BH} 3$-only proteins, resulting in activation of pro-apoptotic proteins and apoptosis [29]. In the latter model, $\mathrm{BH} 3$-only proteins are divided into two 
subgroups: activators including Bim, PUMA, and truncated $\mathrm{Bid}$ (tBid), and inactivators including the other BH3-only proteins. Activator $\mathrm{BH} 3$-only proteins are inhibited by antiapoptotic proteins. Inactivator $\mathrm{BH} 3$-only proteins inhibit this interaction, resulting in activation of activator $\mathrm{BH} 3$-only protein leading apoptosis [29]. The Bcl-2 family plays an important role in TBI. BH3-only proteins including Bad [30], Bim [31], Noxa [32], and PUMA [33] contribute to apoptotic cell death after neuronal damage. Increased expression of Bax has been observed in the nucleus of apoptotic cells following experimental TBI, while increased expression of Bcl-2 was observed in the neuron that survives following experimental TBI and in the damaged brain of human $[10,16]$.

\section{Bcl-2 Family Downstream Interactions}

Proteins in the intermembrane space, including cytochrome c $[34,35]$, second mitochondria-derived activator of caspase (Smac) [36], endonuclease G (Endo G), and AIF [23], are released and interact with each other after TBI. Then their interaction results in the release of the pro-apoptotic proteins [37]. Cytochrome c interacts with procaspase-9 and apoptotic protein-activating factor-1 (apaf-1), and forms the apoptosome, resulting in activation of procaspase-9 [38, 39]. Caspase- 9 activates procaspase- 3 , then caspase- 3 degrades inhibitors of caspase-activated DNase, leading to DNA fragmentation and apoptosis. Caspase- 3 can also activate other enzymes after TBI which repair damaged DNA, such as poly (ADPribose) polymerase (PARP) [40]. Despite being involved in necrosis and apoptosis, $89-$ and $21-\mathrm{kDa}$ fragments of PARP are cleaved by caspases and are related to apoptosis after cerebral ischemia [41, 42].

Smac is also involved in caspase activation. After TBI, Smac released from mitochondria binds to and neutralizes the effect of the $\mathrm{X}$ chromosome-linked inhibitor-ofapoptosis protein, resulting in further apoptosis [36].

\section{Apoptosis Independent of Caspase}

Accumulated studies show the importance of the caspaseindependent pathways. Following TBI, apoptosis-inducing factor (AIF), a flavoprotein with NADH oxidase that resides in the mitochondrial intermembrane space, is released into the cytosol via membrane permeabilization. AIF then translocates to the nucleus and induces apoptosis [43]. This apoptotic pathway is also independent of cytochrome c, Apaf-1, and caspases [44, 45]. Apart from these, PARP-1, cyclophilin A, and HSP-70 are involved in regulation of AIF release from mitochondria and translocation to the nucleus. Inhibition of PARP-1 has neuroprotective effects after TBI [46]. cyclophilins are a family of peptidylprolyl cis-trans isomerases [47]. Cyclophilin A participates in the nuclear translocation of AIF from the cytosol to the nucleus and facilitates the chromatolytic effects of AIF [48]. The heat shock proteins of the HSP70 family have neuroprotective effect through their chaperone function [49]. The binding of HSP70 to Apaf-1 and AIF antagonizes their pro-apoptotic effects by inhibiting the formation of the apoptosome and nuclear translocation of AIF [50], respectively. HSP70 overexpression attenuates ischemic brain injury by sequestering AIF [51] and also by inhibiting the caspase-dependent pathway [49]. In contrast to caspase-dependent cell death, AIFmediated apoptosis can occur under impaired bioenergetics status; this can readily be seen in the core lesion following cerebral ischemia [44]. In fact, in energy-depleted states, the mitochondria are more likely to release AIF, which results in caspase-independent apoptosis [52, 53]. Therefore, AIFinduced apoptosis may be more common in severe TBI where impaired bioenergetic conditions are more likely. Conversely in mild TBI, where mitochondrial energy utilization is less of an issue, caspase-mediated apoptosis is more likely. Endo $\mathrm{G}$ is also known to translocate to the nucleus, causing DNA fragmentation in rodent focal cerebral ischemia model, which may be applicable to TBI injury as well [54] (Fig. 1).

\section{Upstream of the Intrinsic Pathway}

Akt is a serine-threonine kinase and is involved in the apoptotic signaling pathway as a major downstream target of PI3-K. The phosphorylation of Akt inactivates Bad following TBI in mice, resulting in inactivation of the apoptotic pathway [55]. Akt also phosphorylates procaspase-9 and caspase-9 and inhibits their activity, resulting in the inactivation of apoptotic pathway in an ischemic stroke model as well [56].

Following TBI in a rodent model, significant mitogenactivated protein kinase (MAPK) is observed which results in the inhibition of pro-apoptotic proteins, such as Bad and Bim, and subsequent reduction in contusion volume and apoptosis [57]. In addition, since a number of Bcl-2 family proteins are regulated by $\mathrm{p} 53$, a well-known tumor suppressor and transcription factor induced by cellular damage, it is not surprising that p53 can also activate a number of intrinsic apoptotic pathways. In rodent models of global cerebral ischemia, p53 translocates to mitochondria, interacts with Bcl-XL, and induces caspase-dependent apoptosis [32].

\section{Extrinsic Pathway of Neuronal Apoptosis}

Extrinsic mechanisms of apoptosis involve cell surface receptors present on multiple cell types, including neurons, and is also referred to as the "death receptor pathway." The binding of extracellular tumor necrosis factor (TNF) to TNF receptor 


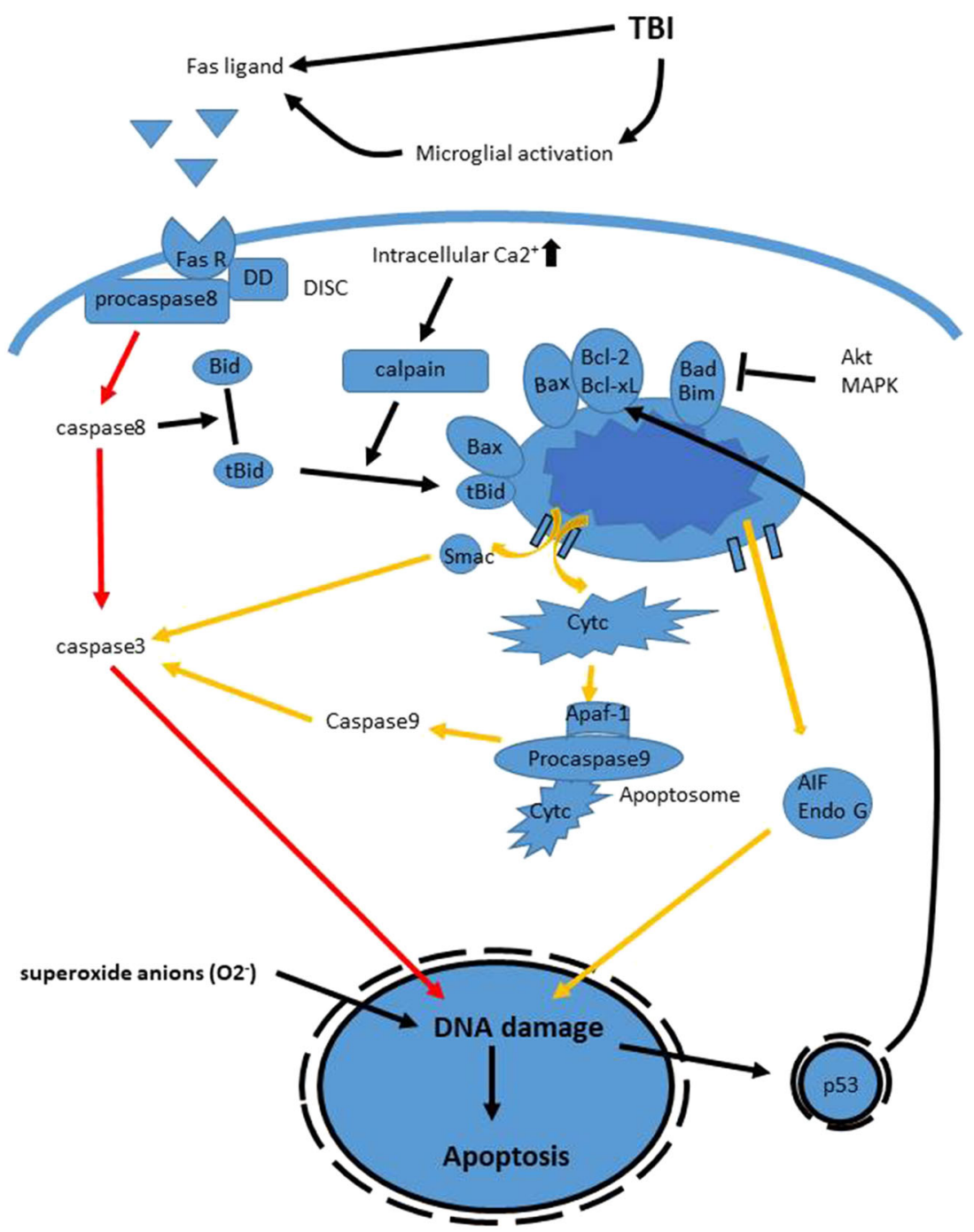

Fig. 1 Signaling cascade of apoptosis in traumatic brain injury (TBI). Extrinsic pathway (red arrows); following TBI, Fas ligand binds to Fas death receptors (FasR) and triggers the recruitment of the death domain protein (DD), which binds to procaspase-8. This complex, death-inducing signaling complex (DISC), activates caspase-8. Activated caspase-8 either results in the cleaving of Bid to truncated active form of Bid (tBid), which integrates the different death pathways at the mitochondrial checkpoint of apoptosis and activates caspase-3. tBid interacts with Bax, which is inhibited by ant-iapoptotic Bcl-2 family proteins, $\mathrm{Bcl}-2$ or Bcl-xL. Interaction of $\mathrm{tBid}$ with $\mathrm{Bax}$ leads to the opening of mitochondrial transition pores, subsequently releasing cytochrome c (Cytc) or second mitochondria-derived activator of caspase (Smac). Once released into the cytosol, Cytc binds with apoptotic protein-activating factor-1 (Apaf1) and procaspase-9 to form an apoptosome, which activates caspase-9, leading to caspase-3-dependent cell death. This pathway also interacts

or extracellular FasL to the Fas receptor triggers recruitment of the cytoplasmic death domain protein (DD), resulting in the death-inducing signaling complex (DISC) [58]. Interestingly, TNF $\alpha$ and Fas knockout mice have significantly smaller brain lesion and favorable memory performance after controlled cortical impact (CCI). These findings emphasize the contribution of death receptors in cell death after TBI [59]. microglia activation. Intrinsic pathway (yellow arrows): TBI elevates cytosolic calcium concentration and activates calpains and mediates cleavage of Bid to Bid. At the mitochondrial intermembrane, tBid interacts with apoptotic proteins and induces caspase-3-dependent pathway. In contrast, apoptosis-inducing factor (AIF) or endonuclease G (Endo G) translocates to the nucleus where it mediates DNA damage and cell death in a caspase-independent manner. In addition, nuclear pathways of neuronal apoptosis are activated in response to DNA damage through activation of $\mathrm{p} 53$, which interacts with bcl-2 family proteins and precedes Cytc release. Mitogen-activated protein kinases (MAPK) and Akt pathway are also inactivate Bad or Bim, resulting in apoptosis. Furthermore, TBI generate superoxide anions, which also causes DNA damage. Both extrinsic and intrinsic pathway interact via Bid and cause DNA damage leading to apoptosis

\section{Cross-talk Between Intrinsic and Extrinsic Pathway}

The extrinsic pathway receives extracellular signals and transduces them to intracellular signals, and the Fas pathway is one of those extracellular signals. Both Fas and Fas ligand (FasL) proteins are upregulated after brain injury $[60$, 
61]. Fas, the death domain (DD), and procaspase- 8 form a protein complex that is referred to as the DISC. DISC activates procaspase- 8 , similar to procaspase- 9 activation by the apoptosome. Caspase- 8 activation is followed by activation of caspase- 3 and caspase- 10 after cerebral ischemia [61]. Bid is a key molecule for cross-talk between extrinsic and intrinsic pathway, which is truncated by caspase- 8 , translocates to mitochondria, interacts with other Bcl-2 family proteins, and cytochrome c release followed by apoptotic cell death [62].

\section{Apoptosis and Oxidative Stress}

It has been thought that mitochondria are the primary source of reactive oxygen species (ROS) involved in ischemiainduced apoptosis, which can be seen in impaired energy metabolism after severe TBI. Previous studies have demonstrated that a variety of stimuli, including hypoxia, excitotoxicity, and $\mathrm{Ca}^{2+}$ influx after cerebral ischemia, produce mitochondrial ROS [63]. ROS is a trigger of the release of cytochrome c and other pro-apoptotic proteins from the mitochondria into the neuronal cytosol, leading to apoptosis and defective gene expression after stroke $[35,64]$. Thus, increasing evidence suggests that oxidative stress and apoptosis are closely linked phenomena in the pathophysiology of ischemic stroke.

\section{Neuronal Apoptosis Driven by the Other Cell Types}

Microglia is the primary immune cell in the CNS and maintains CNS homeostasis by engulfing and clearing neurons that die as a result of apoptosis; they also participate in brain development and neuronal plasticity [65-67]. After TBI, microglia drive neuronal apoptosis via the release of superoxide anion [68], nerve growth factor [69], and tumor necrosis factor (TNF) [70]. However, the role of microglia in TBI remains to be elucidated. Wang et al. demonstrated that microglial depletion significantly reduced neuronal apoptosis following moderate fluid percussion injury in rodents [71]. On the other hand, Bennett et al. [72] demonstrated that inhibition of microglia did not contribute to acute axon degeneration after multiple concussive injury. Hanlon et al. [73] demonstrated that microglia depletion with clodronate caused an increase in neurodegeneration in a rat $\mathrm{CC}$ model, possibly due to a decrease in the clearance of dying cells. Therefore, the impact of the microglia may vary depending on the type of injured cells and TBI models. Astrocytes are highly connected via gap junctions that allow for intercellular exchange of metabolites, ions, and small molecules. Lin et al. [74] demonstrated that gap junctions propagate intercellular signals, which cause cell injury induced by intracellular calcium overload, oxidative stress, and metabolic impairment in cerebral ischemia. Connexin $43(\mathrm{Cx} 43)$ is the mostly studied gap junction protein highly expressed on astrocytes $[75,76]$. In vivo and in vitro study suggested that remote hippocampal apoptosis was associated with spread of apoptotic signal through the astrocytic Cx43 hemi-channels in rodent TBI model [75-77]. Surprisingly, heterozygotic $\mathrm{Cx} 43$ null mice, which express $50 \%$ of the normal $\mathrm{Cx} 43$, showed large lesions compared with wild-type mice in focal cerebral ischemia in rodents [78]. Therefore, implication of $\mathrm{Cx} 43$ in neuronal damage spread has remained unknown.

\section{Apoptosis in the Chronic Phase of TBI}

There are many common features among neurodegenerative diseases, including inflammatory and neurovascular pathologies associated with irregular accumulation of tau protein [79], blood-brain barrier permeability [80], abnormal angiogenesis, and apoptosis [81]. Although limited evidence exists, the chronic sequelae of TBI might also share these pathologies [82]. Furthermore, there is a pathological link between TBI and other neurodegenerative diseases, such as Alzheimer's and Parkinson's diseases. All the aforementioned diseases have some abnormal proteinaceous accumulation, whether it be amyloid $\beta$, tau protein, or both, suggesting a shared spectrum between them [83]. Previous preclinical studies in rodents exposed to CCI demonstrate neuronal degeneration and total brain atrophy that occurs over at least 1 year [81, 84]. Another study demonstrated upregulation of cleavedcaspase- 3 in the white matter of the corpus callosum 3 months after CCI in rats, suggesting an association between chronic neurodegeneration and apoptotic cell death [85]. Furthermore, in CCI-exposed rats, caspase- 3 was co-localized with tau accumulation, indicating a possible correlation between apoptosis and tau during the chronic phase of TBI [86]. Further study may allow us to understand association of apoptosis with the chronic sequelae of TBI.

\section{Apoptosis and Mild TBI}

Emerging evidence suggests that repeated mild TBI may have a great cumulative effect on brain functions, leading to chronic persistent neurological symptoms due to the neurodegeneration [87-89]. In mild TBI, cellular metabolism is disturbed and microstructural damage occurs and results in both biochemical and vascular autoregulation abnormalities [90]. Although cell death is not typically observed acutely after a single mild TBI, some studies indicated a potential for neuronal cell death through apoptosis in repeated mild TBI [91, 92]. Microarray analysis in rodent brains exposed to repeated mild TBI at 17 weeks showed significantly altered the expression 
Table 2 Expressed apoptotic biomarkers in human serum and/or cerebrospinal fluid following traumatic brain injuries

\begin{tabular}{lllll}
\hline Author & Biomarker & Evaluated time point & Samples & Clinical implication \\
\hline Uzan [94] & Caspase-3 & $1-10$ days & CSF & Correlation with increased intracranial pressure \\
Härter [95] & Activated caspase-3 & $1-14$ days & CSF & Peak at 2-5 days after injury \\
Lorente [96] & Activated caspase-3 & 1 day & Serum & Association with 30-day mortality \\
Darwish [97] & Caspase-9 & 2 hrs-3 days & CSF & Correlation with poor neurological outcome \\
Lorente [98] & CCCK-18 & On admission & Serum & Association with 30-day mortality \\
Pineda [99] & SBDP120 & 6 hrs-5 days & CSF & Correlation with severity of injury \\
Mondello [100] & SBDP120 & Admission-7 days & CSF & Higher level in the fatal patients \\
Shahim [101] & Caspase-cleaved tau & 1 h-6 days & Serum & Higher levels in postconcussion sample \\
\hline
\end{tabular}

$C S F$ cerebrospinal fluid, $C C C K-18$ caspase-cleaved cytokeratin-18, SBDP120 spectrin breakdown products 120

level of 87 genes which are involved in apoptosis, stress response, metabolism, and synaptic plasticity, suggesting an association with chronic neuronal degeneration [89]. Furthermore, repeated, mild TBI led to a significant reduction in neuronal cells and substantially increased microglial activation in ipsilateral and contralateral hippocampi at 28 days after fluid percussion injury in rats [93]. Thus, sustained activation of microglia may also contribute to the chronic spread of cell damage via apoptosis.

\section{Apoptotic Biomarker in Serum and/or Cerebrospinal Fluid in Human}

Several clinical studies have investigated apoptotic biomarkers in serum and/or cerebrospinal fluid (CSF) following TBI with different severities and time points (Table 2). Increase in the level of caspase-3 and caspase-9 is indicative of involvement of apoptotic pathway [94-97]. Levels of caspase-specific cleavage products such as caspase-cleaved cytokeratin-18 (CCCK-18), caspase-cleaved tau, and caspase-specific spectrin breakdown products (SBDP) 120 are also suggestive of cellular involvement of particular cell types and demonstrate injury mechanisms [98-101].

\section{Apoptosis Following TBI as Therapeutic Targets}

In the central nervous system, apoptosis is a mechanism by which the neurons that have not formed functional synaptic connections are removed. In addition, during development, apoptosis contributes to neuronal plasticity [102]. One of the features of apoptosis is minimal activation of the immune system over the course of cell death, and thus the surrounding cells are able to remain relatively unaffected. Therefore, neuronal apoptosis seems to be a reasonable mechanism to limit collateral damage following ischemic or traumatic brain injury. In pathological conditions, treatment with tetrapeptide caspase-3 inhibitor (z-DEVD-fmk) at $24 \mathrm{~h}$ or overexpression of the anti-apoptotic protein bcl-2 significantly reduced brain damage following CCI in rodents, although motor and cognitive deficits were not improved [9]. However, pretreatment with the caspase-3 inhibitor improved neurological outcome as well as reduced lesion size following FPI in rats $[8,103$, 104]. Similarly, treatment with a pan-caspase inhibitor (zVAD-fmk) after FPI improved functional outcome in rats by attenuating mitochondrial release of cytochrome c $[105,106]$. Moreover, depletion of PARP and early treatment with inhibitors of PARP at $24 \mathrm{~h}$ after TBI also improved functional outcome by limiting caspaseindependent pathway mediated by AIF following CCI in rodents [46, 107-109]. Therefore, anti-apoptotic treatment targeting multiple apoptotic pathways may have to be applied within appropriate therapeutic time window.

Furthermore, several anti-apoptotic drugs with multifunctional activities were evaluated in clinical studies [110]. Statins exert anti-inflammatory effects by limiting the production of inflammatory mediators, glial cell activation, and cerebral edema in the rodent TBI model [111-113]. They also decrease apoptosis after trauma and effectively alter the ratio of anti-apoptotic to apoptotic factors and improved the cognitive function [114]. A small, prospective, randomized, doubleblind clinical trial showed a slight improvement in amnesia and disability following moderate to severe TBI $[115,116]$. However, another prospective clinical study could not show clinical benefit to statin use at the time of moderate or severe TBI [117].

Progesterone attenuated glutamate excitotoxicity [118], membrane lipid peroxidation [119], and inflammation, and also reduced cognitive impairment and neuronal cell death after TBI in preclinical models [120-122]. Two phase 2 randomized controlled clinical trial also improved clinical outcome of moderate to severe TBI patients [123, 124]. However, despite the strong preclinical and early clinical data, a multinational placebo-controlled trial failed to show clinical benefit of progesterone following TBI [125]. 
Table 3 Clinical trial of anti-apoptic drugs for traumatic brain injury

\begin{tabular}{lllll}
\hline Author & Severity of TBI & Anti-apoptotic drugs & Time of treatments & Outcome \\
\hline Tapia [115] & Moderate & Rosuvastatin & Start within 24 h and continue for 10 days & Reduced amnesia \\
Sanchez [116] & Moderate to severe & Rosuvastatin & Start within 24 h and continue for 10 days & Reduced disability \\
Whyte [117] & Moderate to severe & Any statin & Statin use at the time of TBI & Not effective \\
Wright [123] & Moderate to severe & Progesterone & Start within 24 h & Not harmful (phase II) \\
Xiao [124] & Severe & Progesterone & Started within 24 h and & Better neurological \\
& & & continued for 5 days & outcome at 6 months \\
Skolnick [125] & Severe & Progesterone & Started within $8 \mathrm{~h}$ and continued for 5 days & Not effective \\
Mazzeo [126] & Severe & Cyclosporine A & Started within 12 h over 24 h & Higher extracellular fluid \\
& & & & glucose and pyruvate \\
& & & & Increase in cerebral perfusion pressure \\
\hline
\end{tabular}

Another potentially useful agent in TBI could be cyclosporine A, an immunosuppressive agent, which attenuates mitochondrial failure by binding cyclophilin D and stabilizing mitochondrial permeability [126]. Treatment with cyclosporine $\mathrm{A}$ reduced lesion size and improved outcome by preventing the apoptotic cascade-induced mitochondrial dysfunction, which was independent of its immunosuppressive function in a rodent TBI model [48, 127]. A prospective randomized, controlled, double-blinded study of cyclosporine A for severe TBI patients showed a decrease in the lactate to pyruvate ratio via cerebral microdialysis [128], suggesting a decrease in anaerobic metabolism. Since this agent has several disadvantages including biphasic drug response, shows poor BBB permeability, and prolonged use results in chronic immunosuppression in phase I clinical trials [129], further evaluation of this drug is necessary. Phase III clinical trials of cyclosporine A for TBI are in preparation [130]. Clinical trials of anti-apoptotic drugs for human TBI are summarized in Table 3.

TBI involves a highly complex pathology characterized by multiple interacting secondary injury cascades. Therefore, using multiple models and species for preclinical screening should be attempted before clinical translation. Bidirectional translational research between preclinical and clinical investigators is warranted to identify novel signaling pathways, target, and modify them, in the hope of identifying pharmaceuticals that may one day improve TBI outcome.

Acknowledgments Dr. Hanafy receives support from the National Institute of Neurological Disorders and Stroke (R21NS099606 and R01NS109174) and the American Heart Association Grant in Aid (17GRNT33670058).

Required Author Forms Disclosure Forms provided by the authors are available with the online version of this article.

Author Contributions YA and $\mathrm{KAH}$ were involved in drafting and editing the manuscript and figures. Both authors consent to this publication.

\section{Compliance with Ethical Standards}

Conflict of Interest The authors declare that they have no conflict of interest.

\section{References}

1. Taylor CA, Bell JM, Breiding MJ, Xu L. Traumatic Brain InjuryRelated Emergency Department Visits, Hospitalizations, and Deaths - United States, 2007 and 2013. MMWR Surveill Summ 2017;66:1-16.

2. Loane DJ, Faden AI. Neuroprotection for traumatic brain injury: translational challenges and emerging therapeutic strategies. Trends Pharmacol Sci 2010;31:596-604.

3. Bramlett HM, Dietrich WD, Green EJ, Busto R. Chronic histopathological consequences of fluid-percussion brain injury in rats: effects of post-traumatic hypothermia. Acta Neuropathol 1997;93: 190-199.

4. Colicos MA, Dixon CE, Dash PK. Delayed, selective neuronal death following experimental cortical impact injury in rats: possible role in memory deficits. Brain Res 1996;739:111-119.

5. Dietrich WD, Alonso O, Halley M. Early microvascular and neuronal consequences of traumatic brain injury: a light and electron microscopic study in rats. J Neurotrauma 1994;11:289-301.

6. Hicks R, Soares H, Smith D, McIntosh T. Temporal and spatial characterization of neuronal injury following lateral fluidpercussion brain injury in the rat. Acta Neuropathol 1996;91: 236-246.

7. Gavrieli Y, Sherman Y, Ben-Sasson SA. Identification of programmed cell death in situ via specific labeling of nuclear DNA fragmentation. J Cell Biol 1992;119:493-501.

8. Nakamura M, Raghupathi R, Merry DE, Scherbel U, Saatman $\mathrm{KE}$, Mcintosh TK. Overexpression of Bcl-2 is neuroprotective after experimental brain injury in transgenic mice. J Comp Neurol 1999;412:681-692.

9. Raghupathi R, Fernandez SC, Murai H, et al. BCL-2 overexpression attenuates cortical cell loss after traumatic brain injury in transgenic mice. J Cereb Blood Flow Metab 1998;18:1259-1269.

10. Conti AC, Raghupathi R, Trojanowski JQ, McIntosh TK. Experimental brain injury induces regionally distinct apoptosis during the acute and delayed post-traumatic period. J Neurosci 1998;18:5663-5672. 
11. Clark RS, Chen J, Watkins SC, et al. Apoptosis-suppressor gene bcl-2 expression after traumatic brain injury in rats. J Neurosci 1997;17:9172-9182.

12. Kaya SS, Mahmood A, Li Y, Yavuz E, Göksel M, Chopp M. Apoptosis and expression of p53 response proteins and cyclin D1 after cortical impact in rat brain. Brain Res 1999;818:23-33.

13. Fox GB, Fan L, Levasseur RA, Faden AI. Sustained sensory/ motor and cognitive deficits with neuronal apoptosis following controlled cortical impact brain injury in the mouse. J Neurotrauma 1998;15:599-614.

14. Dixon CE, Clifton GL, Lighthall JW, Yaghmai AA, Hayes RL. A controlled cortical impact model of traumatic brain injury in the rat. J Neurosci Methods 1991;39:253-262.

15. Hamm RJ, Dixon CE, Gbadebo DM, et al. Cognitive deficits following traumatic brain injury produced by controlled cortical impact. J Neurotrauma 1992;9:11-20.

16. Clark RS, Kochanek PM, Chen M, et al. Increases in Bcl-2 and cleavage of caspase- 1 and caspase-3 in human brain after head injury. FASEB J 1999;13:813-821.

17. Smith FM, Raghupathi R, MacKinnon MA, et al. TUNELpositive staining of surface contusions after fatal head injury in man. Acta Neuropathol 2000;100:537-545.

18. Dressler J, Hanisch U, Kuhlisch E, Geiger KD. Neuronal and glial apoptosis in human traumatic brain injury. Int J Legal Med 2007;121:365-375

19. Fowler J, MacKinnon MA, Raghupathi R, Saatman KE, McIntosh TK, Graham DI. Age does not influence DNA fragmentation in the hippocampus after fatal traumatic brain injury in young and aged humans compared with controls. Clin Neuropathol 2002;21:156-162.

20. Niizuma K, Yoshioka H, Chen H, et al. Mitochondrial and apoptotic neuronal death signaling pathways in cerebral ischemia. Biochim Biophys Acta 2010;1802:92-99.

21. Mergenthaler P, Dirnagl U, Meisel A. Pathophysiology of stroke: lessons from animal models. Metab Brain Dis 2004;19:151-167.

22. Dirnagl U, Iadecola C, Moskowitz MA. Pathobiology of ischaemic stroke: an integrated view. Trends Neurosci 1999;22:391397.

23. Culmsee $\mathrm{C}$, Zhu C, Landshamer S, et al. Apoptosis-inducing factor triggered by poly(ADP-ribose) polymerase and Bid mediates neuronal cell death after oxygen-glucose deprivation and focal cerebral ischemia. J Neurosci 2005;25:10262-10272.

24. Love S. Apoptosis and brain ischaemia. Prog Neuropsychopharmacol Biol Psychiatry 2003;27:267-282.

25. Wang KK. Calpain and caspase: can you tell the difference. Trends Neurosci 2000;23:20-26.

26. Yamada KH, Kozlowski DA, Seidl SE, et al. Targeted gene inactivation of calpain-1 suppresses cortical degeneration due to traumatic brain injury and neuronal apoptosis induced by oxidative stress. J Biol Chem 2012;287:13182-13193.

27. Toescu EC. Apoptosis and cell death in neuronal cells: where does Ca2+ fit in. Cell Calcium 1998;24:387-403.

28. Weber JT. Altered calcium signaling following traumatic brain injury. Front Pharmacol 2012;3:60.

29. Kim H, Rafiuddin-Shah M, Tu HC, et al. Hierarchical regulation of mitochondrion-dependent apoptosis by BCL-2 subfamilies. Nat Cell Biol 2006;8:1348-1358.

30. Kamada H, Nito C, Endo H, Chan PH. Bad as a converging signaling molecule between survival PI3-K/Akt and death JNK in neurons after transient focal cerebral ischemia in rats. $\mathrm{J}$ Cereb Blood Flow Metab 2007;27:521-533.

31. Okuno S, Saito A, Hayashi T, Chan PH. The c-Jun N-terminal protein kinase signaling pathway mediates Bax activation and subsequent neuronal apoptosis through interaction with Bim after transient focal cerebral ischemia. J Neurosci 2004;24:7879-7887.
32. Endo H, Kamada H, Nito C, Nishi T, Chan PH. Mitochondrial translocation of p53 mediates release of cytochrome c and hippocampal CA1 neuronal death after transient global cerebral ischemia in rats. J Neurosci 2006;26:7974-7983.

33. Niizuma K, Endo H, Nito C, Myer DJ, Chan PH. Potential role of PUMA in delayed death of hippocampal CA1 neurons after transient global cereb ral ischemia. Stroke 2009;40:618-625.

34. Fujimura M, Morita-Fujimura Y, Kawase M, et al. Manganese superoxide dismutase mediates the early release of mitochondrial cytochrome $\mathrm{C}$ and subsequent DNA fragmentation after permanent focal cerebral ischemia in mice. J Neurosci 1999;19:3414 3422 .

35. Kirkland RA, Windelborn JA, Kasprzak JM, Franklin JL. A Baxinduced pro-oxidant state is critical for cytochrome c release during programmed neuronal death. J Neurosci 2002;22:6480-6490.

36. Saito A, Hayashi T, Okuno S, Ferrand-Drake M, Chan PH. Interaction between XIAP and Smac/DIABLO in the mouse brain after transient focal cerebral ischemia. J Cereb Blood Flow Metab 2003;23:1010-1019.

37. Merry DE, Korsmeyer SJ. Bcl-2 gene family in the nervous system. Annu Rev Neurosci 1997;20:245-267.

38. Li P, Nijhawan D, Budihardjo I, et al. Cytochrome c and dATPdependent formation of Apaf-1/caspase-9 complex initiates an apoptotic protease cascade. Cell 1997;91:479-489.

39. Zou H, Henzel WJ, Liu X, Lutschg A, Wang X. Apaf-1, a human protein homologous to $\mathrm{C}$. elegans CED-4, participates in cytochrome c-depe ndent activation of caspase-3. Cell 1997;90:405413.

40. LaPlaca MC, Raghupathi R, Verma A, et al. Temporal patterns of poly(ADP-ribose) polymerase activation in the cortex following experimental brain injury in the rat. J Neurochem 1999;73:205213.

41. Chaitanya GV, Babu PP. Differential PARP cleavage: an indication of heterogeneous forms of cell death and involvement of multiple proteases in the infarct of focal cerebral ischemia in rat. Cell Mol Neurobiol 2009;29:563-573.

42. Greenberg DS. Medicine and public affairs. FDA: poor marks for its self-investigation. N Engl J Med 1976;294:1465-1466.

43. Zhang X, Chen J, Graham SH, et al. Intranuclear localization of apoptosis-inducing factor (AIF) and large scale DNA fragmentation after traumatic brain injury in rats and in neuronal cultures exposed to peroxynitrite. J Neurochem 2002;82:181-191.

44. Cregan SP, Dawson VL, Slack RS. Role of AIF in caspasedependent and caspase-independent cell death. Oncogene 2004;23:2785-2796.

45. Candé C, Vahsen N, Garrido C, Kroemer G. Apoptosis-inducing factor (AIF): caspase-independent after all. Cell Death Differ 2004; 11:591-595.

46. Whalen MJ, Clark RS, Dixon CE, et al. Reduction of cognitive and motor deficits after traumatic brain injury in mice deficient in poly(ADP-ribose) polymerase. J Cereb Blood Flow Metab 1999; 19:835-842.

47. Galat A. Peptidylprolyl cis/trans isomerases (immunophilins): biological diversity-targets-functions. Curr Top Med Chem 2003;3: 1315-1347.

48. Candé C, Vahsen N, Kouranti I, et al. AIF and cyclophilin A cooperate in apoptosis-associated chromatinolysis. Oncogene 2004;23:1514-1521.

49. Parcellier A, Gurbuxani S, Schmitt E, Solary E, Garrido C. Heat shock proteins, cellular chaperones that modulate mitochondrial cell death pathways. Biochem Biophys Res Commun 2003;304: 505-512.

50. Gurbuxani S, Schmitt E, Cande C, et al. Heat shock protein 70 binding inhibits the nuclear import of apoptosis-inducing factor. Oncogene 2003;22:6669-6678. 
51. Matsumori Y, Hong SM, Aoyama K, et al. Hsp70 overexpression sequesters AIF and reduces neonatal hypoxic/ischemic brain injury. J Cereb Blood Flow Metab 2005;25:899-910.

52. Alano CC, Ying W, Swanson RA. Poly(ADP-ribose) polymerase1-mediated cell death in astrocytes requires NAD+ depletion and mitochondrial permeability transition. J Biol Chem 2004;279: 18895-18902.

53. Moubarak RS, Yuste VJ, Artus C, et al. Sequential activation of poly(ADP-ribose) polymerase 1, calpains, and Bax is essential in apoptosis-inducing factor-mediated programmed necrosis. Mol Cell Biol 2007;27:4844-4862.

54. Lee BI, Lee DJ, Cho KJ, Kim GW. Early nuclear translocation of endonuclease $\mathrm{G}$ and subsequent DNA fragmentation after transient focal cerebral ischemia in mice. Neurosci Lett 2005;386: 23-27.

55. Noshita N, Lewén A, Sugawara T, Chan PH. Akt phosphorylation and neuronal survival after traumatic brain injury in mice. Neurobiol Dis 2002;9:294-304.

56. Wang SJ, Omori N, Li F, et al. Potentiation of Akt and suppression of caspase- 9 activations by electroacupuncture after transient middle cerebral artery occlusion in rats Neurosci Lett 2002;331:115118.

57. Mori T, Wang X, Jung JC, et al. Mitogen-activated protein kinase inhibition in traumatic brain injury: in vitro and in vivo effects. J Cereb Blood Flow Metab 2002;22:444-452.

58. Salvesen GS, Dixit VM. Caspase activation: the inducedproximity model. Proc Natl Acad Sci USA 1999;96:1096410967.

59. Bermpohl D, You Z, Lo EH, Kim HH, Whalen MJ. TNF alpha and Fas mediate tissue damage and functional outcome after traumatic brain injury in mice. J Cereb Blood Flow Metab 2007;27:18061818.

60. Rosenbaum DM, Gupta G, D'Amore J, et al. Fas (CD95/APO-1) plays a role in the pathophysiology of focal cerebral ischemia. J Neurosci Res 2000;61:686-692.

61. Jin K, Graham SH, Mao X, Nagayama T, Simon RP, Greenberg DA. Fas (CD95) may mediate delayed cell death in hippocampal CA1 sector after global cerebral ischemia. J Cereb Blood Flow Metab 2001;21:1411-1421.

62. Plesnila N, Zinkel S, Le DA, et al. BID mediates neuronal cell death after oxygen/ glucose deprivation and focal cerebral ischemia. Proc Natl Acad Sci USA 2001;98:15318-15323.

63. Bell JD. Molecular cross talk in traumatic brain injury. J Neurosci 2007;27:2153-2154.

64. Sugawara T, Lewén A, Gasche Y, Yu F, Chan PH. Overexpression of SOD1 protects vulnerable motor neurons after spinal cord injury by attenuating mitochondrial cytochrome $\mathrm{c}$ release. FASEB J 2002;16:1997-1999.

65. Lawson LJ, Perry VH, Gordon S. Turnover of resident microglia in the normal adult mouse brain. Neuroscience 1992;48:405-415.

66. Tremblay MÈ, Stevens B, Sierra A, Wake H, Bessis A, Nimmerjahn A. The role of microglia in the healthy brain. $\mathrm{J}$ Neurosci 2011;31:16064-16069.

67. Marín-Teva JL, Dusart I, Colin C, Gervais A, van Rooijen N, Mallat M. Microglia promote the death of developing Purkinje cells. Neuron 2004;41:535-547.

68. Salter MW, Stevens B. Microglia emerge as central players in brain disease. Nat Med 2017;23:1018-1027.

69. Frade JM, Barde YA. Microglia-derived nerve growth factor causes cell death in the developing retina. Neuron 1998;20:35-41.

70. Sedel F, Béchade C, Vyas S, Triller A. Macrophage-derived tumor necrosis factor alpha, an early developmental signal for motoneuron death. J Neurosci 2004;24:2236-2246.

71. Wang CF, Zhao CC, Liu WL, et al. Depletion of Microglia Attenuates Dendritic Spine Loss and Neuronal Apoptosis in the
Acute Stage of Moderate Traumatic Brain Injury in Mice. J Neurotrauma 2020;37:43-54.

72. Bennett RE, Brody DL. Acute reduction of microglia does not alter axonal injury in a mouse model of repetitive concussive traumatic brain injury. J Neurotrauma 2014;31:1647-1663.

73. Hanlon LA, Raghupathi R, Huh JW. Depletion of microglia immediately following traumatic brain injury in the pediatric rat: Implications for cellular and behavioral pathology. Exp Neurol 2019;316:39-51.

74. Lin JH, Weigel H, Cotrina ML, et al. Gap-junction-mediated propagation and amplification of cell injury. Nat Neurosci 1998;1:494 500 .

75. Ohsumi A, Nawashiro H, Otani N, Ooigawa H, Toyooka T, Shima $\mathrm{K}$. Temporal and spatial profile of phosphorylated connexin 43 after traumatic brain injury in rats. J Neurotrauma 2010;27: $1255-1263$.

76. Rovegno M, Soto PA, Sáez PJ, Naus CC, Sáez JC, von Bernhardi R. Connexin 43 hemichannels mediate secondary cellular damage spread from the trauma zone to distal zones in astrocyte monolayers. Glia 2015;63:1185-1199.

77. Frantseva MV, Kokarovtseva L, Naus CG, Carlen PL, MacFabe D, Perez Velazquez JL. Specific gap junctions enhance the neuronal vulnerability to brain traumatic injury. J Neurosci 2002;22: 644-653.

78. Siushansian R, Bechberger JF, Cechetto DF, Hachinski VC, Naus CC. Connexin 43 null mutation increases infarct si ze after stroke. J Comp Neurol 2001;440:387-394.

79. Holroyd KA, Penzien DB. Meta-analysis minus the analysis: a prescription for confusio n. Pain 1989;39:359-363.

80. Carvey PM, Hendey B, Monahan AJ. The blood-brain barrier in neurodegenerative disease: a rhetorical perspective. J Neurochem 2009;111:291-314.

81. Mattson MP. Apoptosis in neurodegenerative disorders. Nat Rev Mol Cell Biol 2000;1:120-129.

82. Bailes JE, Petraglia AL, Omalu BI, Nauman E, Talavage T. Role of subconcussion in repetitive mild traumatic brain injury. J Neurosurg 2013;119:1235-1245.

83. Daneshvar DH, Goldstein LE, Kiernan PT, Stein TD, McKee AC. Post-traumatic neurodegeneration and chronic traumatic encephalopathy. Mol Cell Neurosci 2015;66:81-90.

84. Smith DH, Chen XH, Pierce JE, et al. Progressive atrophy and neuron death for one year following brain trauma in the rat. J Neurotrauma 1997;14:715-727.

85. Bramlett HM, Dietrich WD. Quantitative structural changes in white and gray matter 1 year following traumatic brain injury in rats. Acta Neuropathol 2002;103:607-614.

86. Glushakova OY, Glushakov AO, Borlongan CV, Valadka AB, Hayes RL, Glushakov AV. Role of Caspase-3-Mediated Apoptosis in Chronic Caspase-3-Cleaved Tau Accumulation and Blood-Brain Barrier Damage in the Corpus Callosum after Traumatic Brain Injury in Rats. J Neurotrauma 2018;35:157-173.

87. Gaetz M, Goodman D, Weinberg H. Electrophysiological evidence for the cumulative effects of concussion. Brain Inj 2000;14:1077-1088.

88. Nakajima Y, Horiuchi Y, Kamata H, Yukawa M, Kuwabara M, Tsubokawa T. Distinct time courses of secondary brain damage in the hippocampus following brain concussion and contusion in rats. Tohoku J Exp Med 2010;221:229-235.

89. Luo Y, Zou H, Wu Y, Cai F, Zhang S, Song W. Mild traumatic brain injury induces memory deficits with alteration of gene expression

90. Luo Y, Zou H, Wu Y, Cai F, Zhang S, Song W. Mild traumatic brain injury induces memory deficits with alteration of gene expression profile. Sci Rep 2017;7:10846.

91. Dikranian K, Cohen R, Mac Donald C, et al. Mild traumatic brain injury to the infant mouse causes robust white matter axonal 
degeneration which precedes apoptotic death of cortical and thalamic neurons. Exp Neurol 2008;211:551-560.

92. Matser JT, Kessels AG, Jordan BD, Lezak MD, Troost J. Chronic traumatic brain injury in professional soccer players. Neurology 1998;51:791-796.

93. Aungst SL, Kabadi SV, Thompson SM, Stoica BA, Faden AI. Repeated mild traumatic brain injury causes chronic neuroinflammation, changes in hippocampal synaptic plasticity, and associated cognitive deficits. J Cereb Blood Flow Metab 2014;34:12231232.

94. Uzan M, Erman H, Tanriverdi T, Sanus GZ, Kafadar A, Uzun H. Evaluation of apoptosis in cerebrospinal fluid of patients with severe head injury. Acta Neurochir (Wien) 2006;148:1157-64; discussion.

95. Härter L, Keel M, Hentze H, Leist M, Ertel W. Caspase-3 activity is present in cerebrospinal fluid from patients with traumatic brain injury. J Neuroimmunol 2001;121:76-78.

96. Lorente L, Martín MM, Argueso M, et al. Serum caspase-3 levels and mortality are associated in patients with severe traumatic brain injury. BMC Neurol 2015;15:228.

97. Darwish RS, Amiridze NS. Detectable levels of cytochrome C and activated caspase-9 in cerebrospinal fluid after human traumatic brain injury. Neurocrit Care 2010;12:337-341.

98. Lorente L, Martín MM, González-Rivero AF, et al. Serum levels of caspase-cleaved cytokeratin-18 in patients with severe traumatic brain injury are associated with mortality: a pilot study. PLoS ONE 2015;10:e121739.

99. Pineda JA, Lewis SB, Valadka AB, et al. Clinical significance of alphaII-spectrin breakdown products in cerebrospinal fluid after severe traumatic brain injury. J Neurotrauma 2007;24:354-366.

100. Mondello S, Robicsek SA, Gabrielli A, et al. $\alpha$ II-spectrin breakdown products (SBDPs): diagnosis and outcome in severe traumatic brain injury patients. J Neurotrauma 2010;27:1203-1213.

101. Shahim P, Linemann T, Inekci D, et al. Serum Tau Fragments Predict Return to Play in Concussed Professional Ice Hockey Players. J Neurotrauma 2016;33:1995-1999.

102. Oppenheim RW. Cell death during development of the nervous system. Annu Rev Neurosci 1991;14:453-501.

103. Yakovlev AG, Knoblach SM, Fan L, Fox GB, Goodnight R, Faden AI. Activation of CPP32-like caspases contributes to neuronal apoptosis and neurological dysfunction after traumatic brain injury. J Neurosci 1997;17:7415-7424.

104. Clark RS, Kochanek PM, Watkins SC, et al. Caspase-3 mediated neuronal death after traumatic brain injury in rats. J Neurochem 2000;74:740-753.

105. Knoblach SM, Nikolaeva M, Huang X, et al. Multiple caspases are activated after traumatic brain injury: evidence for involvement in functional outcome. J Neurotrauma 2002;19:1155-1170

106. Clark RS, Nathaniel PD, Zhang X, et al. boc-Aspartyl(OMe)fluoromethylketone attenuates mitochondrial release of cytochrome $\mathrm{c}$ and delays brain tissue loss after traumatic brain injury in rats. J Cereb Blood Flow Metab 2007;27:316-326.

107. Clark RS, Vagni VA, Nathaniel PD, Jenkins LW, Dixon CE, Szabó C. Local administration of the poly(ADP-ribose) polymerase inhibitor INO-1001 prevents NAD+ depletion and improves water maze performance after traumatic brain injury in mice. $\mathrm{J}$ Neurotrauma 2007;24:1399-1405.

108. LaPlaca MC, Zhang J, Raghupathi R, et al. Pharmacologic inhibition of poly(ADP-ribose) polymerase is neuroprotective following traumatic brain injury in rats. J Neurotrauma 2001;18:369376.

109. Yu SW, Wang H, Poitras MF, et al. Mediation of poly(ADP-ribose) polymerase-1-dependent cell death by apoptosis-inducing factor. Science 2002;297:259-263.

110. Vink R, Nimmo AJ. Multifunctional drugs for head injury. Neurotherapeutics 2009;6:28-42.
111. Wang H, Lynch JR, Song P, et al. Simvastatin and atorvastatin improve behavioral outcome, reduce hippocampal degeneration, and improve cerebral blood flow after experimental traumatic brain injury. Exp Neurol 2007;206:59-69.

112. Chen G, Zhang S, Shi J, Ai J, Qi M, Hang C. Simvastatin reduces secondary brain injury caused by cortical contusion in rats: possible involvement of TLR4/NF-kappaB pathway. Exp Neurol 2009;216:398-406.

113. Chen SF, Hung TH, Chen CC, et al. Lovastatin improves histological and functional outcomes and reduces inflammation after experimental traumatic brain injury. Life Sci 2007;81:288-298.

114. Lu D, Qu C, Goussev A, et al. Statins increase neurogenesis in the dentate gyrus, reduce delayed neuronal death in the hippocampal CA3 region, and improve spatial learning in rat after traumatic brain injury. J Neurotrauma 2007;24:1132-1146.

115. Tapia-Perez J, Sanchez-Aguilar M, Torres-Corzo JG, et al. Effect of rosuvastatin on amnesia and disorientation after traumatic brain injury (NCT003229758). J Neurotrauma 2008;25:1011-1017.

116. Sánchez-Aguilar M, Tapia-Pérez JH, Sánchez-Rodríguez JJ, et al. Effect of rosuvastatin on cytokines after traumatic head injury. $\mathrm{J}$ Neurosurg 2013;118:669-675.

117. Whyte J, Ketchum JM, Bogner J, et al. Effects of Statin Treatment on Outcomes after Traumatic Brain Injury. J Neurotrauma [published online: August 28, 2018]. https://doi.org/10.1089/neu.2017. 5545

118. Smith SS. Progesterone administration attenuates excitatory amino acid responses of cerebellar Purkinje cells. Neuroscience 1991;42:309-320.

119. Roof RL, Hoffman SW, Stein DG. Progesterone protects against lipid peroxidation following traumatic brain injury in rats. Mol Chem Neuropathol 1997;31:1-11.

120. Pan DS, Liu WG, Yang XF, Cao F. Inhibitory effect of progesterone on inflammatory factors after experimental traumatic brain injury. Biomed Environ Sci 2007;20:432-438.

121. Pettus EH, Wright DW, Stein DG, Hoffman SW. Progesterone treatment inhibits the inflammatory agents that accompany traumatic brain injury. Brain Res 2005;1049:112-119.

122. He J, Hoffman SW, Stein DG. Allopregnanolone, a progesterone metabolite, enhances behavioral recovery and decreases neuronal loss after traumatic brain injury. Restor Neurol Neurosci 2004;22: 19-31.

123. Wright DW, Kellermann AL, Hertzberg VS, et al. ProTECT: a randomized clinical trial of progesterone for acute traumatic brain injury. Ann Emerg Med 2007;49:391-402, 402.e1-2.

124. Xiao G, Wei J, Yan W, Wang W, Lu Z. Improved outcomes from the administration of progesterone for patients with acute severe traumatic brain injury: a randomized controlled trial. Crit Care 2008;12:R61.

125. Skolnick BE, Maas AI, Narayan RK, et al. A clinical trial of progesterone for severe traumatic brain injury. N Engl J Med 2014;371:2467-2476.

126. Mazzeo AT, Beat A, Singh A, Bullock MR. The role of mitochondrial transition pore, and its modulation, in traumatic brain injury and delayed neurodegeneration after TBI. Exp Neurol 2009;218: 363-370.

127. Mbye LH, Singh IN, Carrico KM, Saatman KE, Hall ED, Comparative neuroprotective effects of cyclosporin A and NIM811, a nonimmunosuppressive cyclosporin A analog, following traumatic brain injury. J Cereb Blood Flow Metab 2009;29: 87-97.

128. Mazzeo AT, Alves OL, Gilman CB, et al. Brain metabolic and hemodynamic effects of cyclosporin A after human severe traumatic brain injury: a microdialysis study. Acta Neurochir (Wien) 2008:150:1019-31; discussion 1031. 
129. Margulies S, Hicks R, Ansel B, et al. Combination therapies for traumatic brain injury: prospective considerations. J Neurotrauma 2009;26:925-939.

130. Karlsson M, Pukenas B, Chawla S, et al. Neuroprotective Effects of Cyclosporine in a Porcine Pre-Clinical Trial of Focal Traumatic
Brain Injury. J Neurotrauma [published online: July 24, 2018]. https://doi.org/10.1089/neu.2018.5706

Publisher's Note Springer Nature remains neutral with regard to jurisdictional claims in published maps and institutional affiliations. 